\title{
Syringomyelia Due to Thoracic Spinal Stenosis With Ossified Ligamentum Flavum
}

\author{
-Case Report-
}

\author{
Atsushi ARAI, ${ }^{1}$ Hideo AIHARA, ${ }^{1}$ Shigeru MIYAKE, ${ }^{2}$ \\ Yusei HANADA, ${ }^{2}$ and Eiji KOHMURA ${ }^{1}$ \\ ${ }^{1}$ Department of Neurosurgery, Kobe University School of Medicine, Kobe, Hyogo; \\ ${ }^{2}$ Department of Neurosurgery, Toyooka Hospital, Toyooka, Hyogo
}

\begin{abstract}
A 50-year-old male presented with back pain and numbness of the lower extremities persisting for 10 years. He had played volleyball for a long period until recently. He had no history of meningitis or traumatic injury. Magnetic resonance imaging revealed a syringomyelia located in the region from T8 to T9 without contrast enhancement or Chiari malformations. Computed tomography showed T9-10 spinal stenosis caused by the right enlarged ossified yellow ligament. Decompressive laminectomy was performed and the ossified ligament removed. Due to the finding of arachnoid thickening and adhesions during the intradural operation, shunting was also performed. Postoperatively, the neuroimaging and clinical findings improved. Syringomyelia is often associated with Chiari malformations, trauma, spinal tumor, hemorrhaging, and meningitis. We suggest that repeated minor mechanical damage caused by physical exercise in addition to long-standing compression of the spinal cord due to spinal spondylosis could induce severe arachnoid fibrotic change similar to adhesive arachnoiditis, which may be one of the main triggers of syringomyelia. Extradural decompressive surgery is considered to be the initial treatment for syringomyelia associated with spinal spondylosis.
\end{abstract}

Key words: syringomyelia, spinal stenosis, ossification of yellow ligament, adhesive arachnoiditis, decompressive surgery

\section{Introduction}

Syringomyelia is often associated with Chiari malformations, trauma, spinal tumor, hemorrhaging, and meningitis. Spinal spondylosis is considered to be a rare cause of syringomyelia. Several cases of syringomyelia caused by cervical spondylosis have been described previously.1,3,5-9,12,14) Long-standing blockade of cerebrospinal fluid (CSF) circulation is considered to be one of the main causes of syringomyelia associated with degenerative diseases of the cervical spine. ${ }^{9)}$ We present an unusual case of syringomyelia due to thoracic spinal stenosis associated with an ossified yellow ligament.

\section{Case Report}

A 50-year-old male presented with slight numbness of the lower extremities and back pain persisting for 10 years. He had been a volleyball player at school and had played volleyball until recently. He had not suffered any meningitis or traumatic injury and had not undergone any previous spinal operations. The numbness in his right leg had deteriorated progressively for 6 months, so he underwent

Received February 25, 2010; Accepted July 20, 2010 a medical examination. Magnetic resonance imaging revealed a syringomyelia located in the region from T8 to T9 without contrast enhancement or Chiari malformations. Computed tomography showed spinal stenosis caused by the right enlarged ossified yellow ligament and disc herniation at T9-10 (Fig. 1). Vibration, position, pain, and temperature sensation were diminished below T12 bilaterally, and the patient showed positive Romberg signs. The deep tendon reflexes of the lower extremities were exaggerated, but no lower extremity weakness or urinary disturbance was present.

T9-11 decompressive laminectomy was performed. The right ossified yellow ligament at T9-10 compressed the dural sac from the lateral posterior direction, so the ligaments were removed to obtain sufficient decompression of the spinal canal. After decompression, the dura mater demonstrated good pulsation. The arachnoid membrane at the allover posterior part of the spinal cord was markedly thickened and adhered partially to the dura mater and mainly to the pia mater (Fig. 2). Since no CSF circulation at the subarachnoid space was found, an incision was made in the dilated cord and the syrinx cavity opened. Attempted division of the tight arachnoid adhesions to the pia mater failed, so a syringo-epiarachnoid shunt was inserted. The dilated cord shrank. 


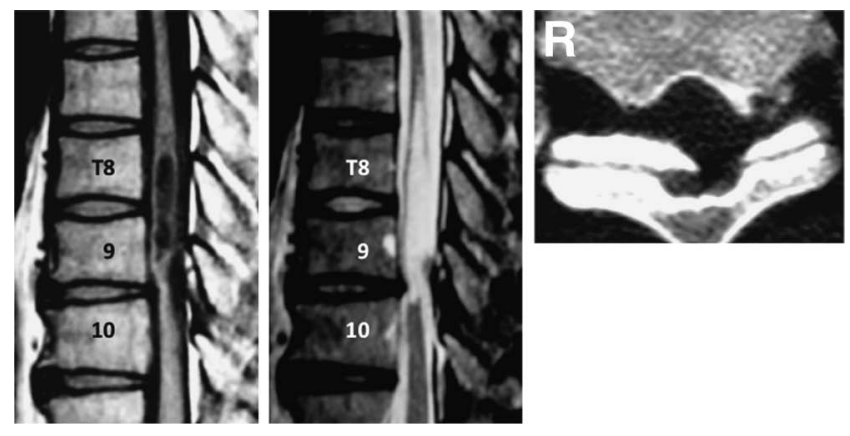

Fig. 1 Preoperative sagittal $T_{1}$-weighted (left) and $T_{2}$-weighted (center) magnetic resonance images showing a syrinx at T8-9 and compression of the spinal cord due to an enlarged ossified yellow ligament at T9-10. Axial computed tomography scan (right) showing the enlarged ossified yellow ligament.

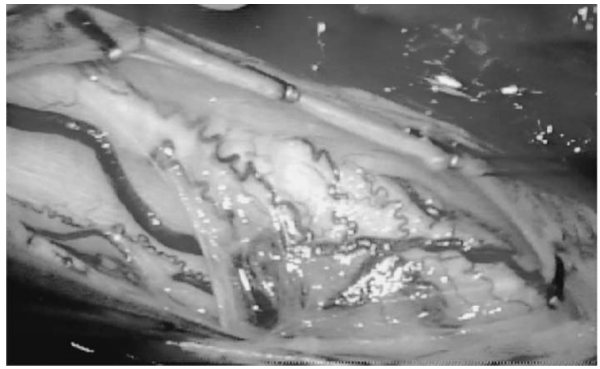

Fig. 2 Intraoperative photograph showing marked arachnoid thickening and adhesions found during intradural surgery.
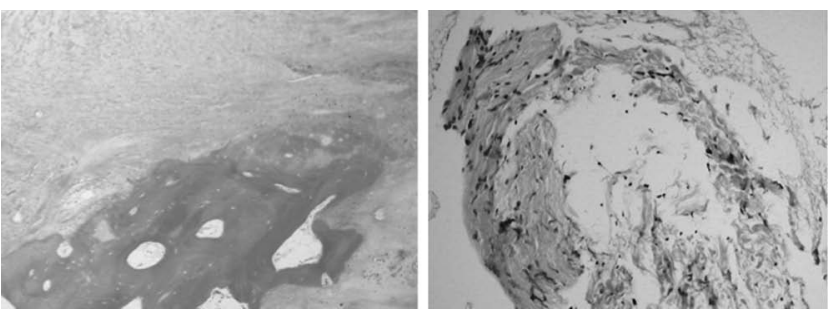

Fig. 3 Photomicrographs showing ossification of the yellow ligament (left) and fibrotic changes in the arachnoid membrane (right). Hematoxylin and eosin stain, original magnification $\times 100$.

Histological examination showed ossification of the yellow ligament, severe fibrosis, and thickening of the arachnoid membrane (Fig. 3). Postoperatively, the syrinx cavity decreased (Fig. 4), and the patient's symptoms also improved.

\section{Discussion}

Syringomyelia primarily due to spinal spondylosis is uncommon, with only 11 previous cases of intramedullary cavity formation caused by cervical spondylosis. ${ }^{1,3,5-9,12,14)}$ Only one previous case of syringomyelia was associated
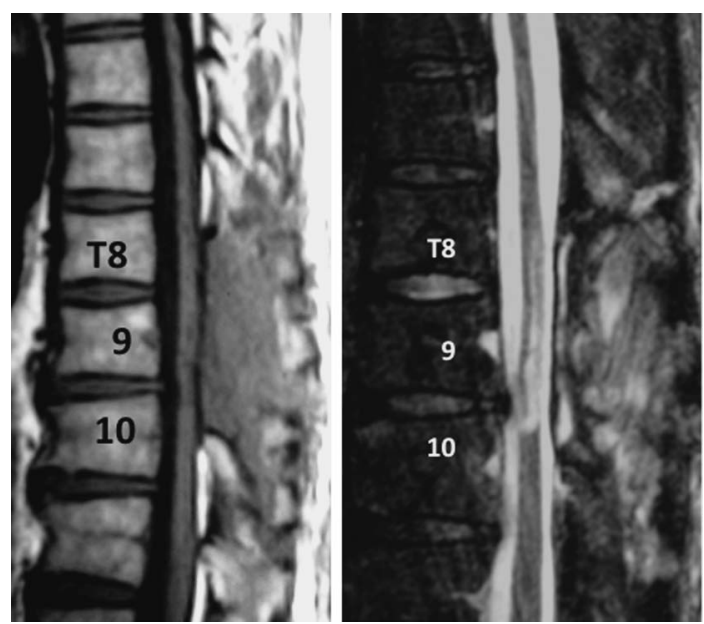

Fig. 4 Sagittal $\mathrm{T}_{1}$-weighted (left) and $\mathrm{T}_{2}$-weighted (right) magnetic resonance images obtained at 1 month after surgery revealing marked reduction of the syrinx.

with cervical ossification of the yellow ligament. ${ }^{5}$ Ossification of the yellow ligament can induce myelopathy, most frequently in the lower thoracic spine. ${ }^{2)}$ Long-standing compression of the spinal cord caused by cervical spondylosis may induce CSF dynamic disorders in the spinal cord parenchyma and the sloshing effect of the pulsatile CSF pressure may enlarge any cavities produced. ${ }^{9}$ In our present case, severe arachnoid adhesions and a syrinx cavity were detected during the intradural surgery. The patient had not suffered from meningitis or traumatic injury and had not undergone any previous spinal operations. Since he had played volleyball for a long period until recently, the spinal cord at the site of thoracic spinal stenosis due to enlarged ossified yellow ligaments might have been exposed to repeated minor mechanical damage induced by the physical exercise. We suggest that longstanding compression of the spinal cord due to an enlarged ossified yellow ligament and repeated minor mechanical damage of the spinal cord at the same site by physical exercise could induce severe arachnoid fibrotic changes such as adhesive arachnoiditis, which may be one of the main causes of syringomyelia.

The pathophysiology of syringomyelia due to adhesive arachnoiditis is still not well understood. Several factors such as spinal surgery, myelography, and meningitis are known to cause adhesive arachnoiditis. Adhesive spinal arachnoiditis is a chronic inflammatory process in the piaarachnoid of the spinal cord. The initial stage of syringomyelia in spinal arachnoiditis is intramedullary cystic degeneration caused by ischemia due to circulatory disturbance in the pia-arachnoid. The blockade of CSF pathways around the spinal cord contributes to the formation of intramedullary cystic cavities. ${ }^{10)}$ Another possibility is that the CSF pressure gradients inside and outside the spinal cord are the generating force behind syrinx formation. ${ }^{4)}$

In previous cases of syringomyelia due to cervical spondylosis, decompressive surgery without an intradural operation resulted in decreases in the size of the syrinx 
cavity and improvements in symptoms. ${ }^{1,5-9,12,14)} \mathrm{Re}-$ storation of CSF flow dynamics between the syrinx and subarachnoid space by decompressive surgery was more effective than simply draining the syrinx cavity for the treatment of syringomyelia without Chiari malformations. ${ }^{11)}$ Decompression of the spinal subarachnoid space may have beneficial effects unless the patient shows longitudinally extensive arachnoiditis. ${ }^{10)}$ Intraoperative color Doppler ultrasonography is used as a guide for performing patient-specific posterior fossa decompressions in patients with Chiari type I malformation. CSF circulation at the cervicomedullary junction can be assessed immediately before opening the dura. ${ }^{13)}$ Intraoperative ultrasonography might be useful to measure the CSF flow at the site of thoracic syrinx and determine the need for shunting following decompression. We performed both decompressive and intradural surgery in the present case, but extradural decompressive surgery is considered to be the initial treatment of choice for syringomyelia associated with spinal spondylosis.

The present case of syringomyelia due to thoracic spinal stenosis associated with enlarged ossified yellow ligament suggests that repeated minor mechanical damage caused by physical exercise in addition to long-standing compression of the spinal cord due to spinal spondylosis could induce severe arachnoid fibrotic change similar to adhesive arachnoiditis, which may be one of the main causes of syringomyelia. Extradural decompressive surgery is considered to be the initial treatment of choice for syringomyelia associated with spinal spondylosis.

\section{References}

1) Ball JR, Little NS: Chiari malformation, cervical disc prolapse and syringomyelia-always think twice. J Clin Neurosci 15: 474-476, 2008

2) Ben Hamouda K, Jemel H, Haouet S, Khaldi M: Thoracic myelopathy caused by ossification of the ligamentum flavum: a report of 18 cases. J Neurosurg 99: 157-161, 2003

3) Butteriss DJ, Birchall D: A case of syringomyelia associated with cervical spondylosis. Br J Radiol 79: e123-e125, 2006
4) Chang HS, Joko M, Matsuo N, Kim SD, Nakagawa H: Subarachnoid pressure-dependent change in syrinx size in a patient with syringomyelia associated with adhesive arachnoiditis. Case report. J Neurosurg Spine 2: 209-214, 2005

5) Fukuzumi Y, Tani S, Isoshima A, Nagashima H, Okuda Y, Abe T: [A case of syringomyelia associated with ossification of the yellow ligament: assessment of surgical outcomes using PVI and Ro]. Sekizui Geka 20: 187-191, 2006 (Japanese)

6) Kaar GF, N'Dow JM, Bashir SH: Cervical spondylotic myelopathy with syringomyelia. Br J Neurosurg 10: 413-415, 1996

7) Kameyama T, Ando T, Fukatsu H, Mizuno T, Takahashi A: [Syringomyelic syndrome secondary to cervical canal stenosis and cervical spondylosis]. Rinsho Shinkeigaku 33: 1179-1183, 1993 (Japanese)

8) Kato N, Tanaka T, Nagashima H, Arai T, Hasegawa Y, Tani $\mathrm{S}$, Abe T: Syrinx disappearance following laminoplasty in cervical canal stenosis associated with Chiari malformation. Neurol Med Chir (Tokyo) 50: 172-174, 2010

9) Kimura R, Park YS, Nakase H, Sakaki T: Syringomyelia caused by cervical spondylosis. Acta Neurochir (Wien) 146: 175-178, 2004

10) Koyanagi I, Iwasaki Y, Hida K, Houkin K: Clinical features and pathomechanisms of syringomyelia associated with spinal arachnoiditis. Surg Neurol 63: 350-355, 2005

11) Lee JH, Chung CK, Kim HJ: Decompression of the spinal subarachnoid space as a solution for syringomyelia without Chiari malformation. Spinal Cord 40: 501-506, 2002

12) Lucci B, Reverberi S, Greco G: Syringomyelia and syringomyelic syndrome by cervical spondylosis. Report on three cases presenting with neurogenic osteoarthropathies. J Neurosurg Sci 25: 169-172, 1981

13) Milhorat TH, Bolognese PA: Tailored operative technique for Chiari type I malformation using intraoperative color Doppler ultrasonography. Neurosurgery 53: 899-905, 2003

14) Rebai R, Boudawara MZ, Ben Yahia M, Mhiri C, Ben Mansour H: [Syringomyelobulbia associated with cervical spondylosis. Pathophysiology and therapeutic implications]. Neurochirurgie 48: 120-123, 2002 (French)

Address reprint requests to: Atsushi Arai, MD, Department of Neurosurgery, Kobe University Graduate School of Medicine, 7-5-2 Kusunoki-cho, Chuo-ku, Kobe 650-0017, Japan. 